\title{
Evidence of long distance airborne transport of porcine reproductive and respiratory syndrome virus and Mycoplasma hyopneumoniae
}

\author{
Scott DeE*, Satoshi Otake, Simone Oliveira, John Deen \\ Swine Disease Eradication Center, University of Minnesota College of Veterinary Medicine, \\ 385C Animal Science/Veterinary Medicine Building 1988 Fitch Avenue, St. Paul, MN 55108, USA
}

(Received 27 January 2009; accepted 17 April 2009)

\begin{abstract}
The ability of porcine reproductive and respiratory syndrome virus (PRRSV) and Mycoplasma hyopneumoniae to be transported over long distances via the airborne route was evaluated. A source population of 300 grow-finish pigs was experimentally inoculated with PRRSV MN-184 and $M$. hyopneumoniae 232 and over a 50-day period, air samples were collected at designated distances from the source herd using a liquid cyclonic collector. Samples were tested for the presence of PRRSV RNA and M. hyopneumoniae DNA by PCR and if positive, further characterized. Of the 306 samples collected, $4(1.3 \%)$ were positive for PRRSV RNA and $6(1.9 \%)$ were positive for M. hyopneumoniae DNA. The PRRSV-positive samples were recovered $4.7 \mathrm{~km}$ to the northwest $(\mathrm{NW})$ of the source population. Four of the M. hyopneumoniae-positive samples were obtained at the NW sampling point; 2 samples at approximately $2.3 \mathrm{~km}$ and the other 2 samples approximately $4.7 \mathrm{~km}$ from the source population. Of the remaining 2 samples, one sample was obtained at the southeast sampling point and the other at the southwest sampling point, with both locations being approximately $4.7 \mathrm{~km}$ from the source. The four PRRSV-positive samples contained infectious virus and were $\geq 98.8 \%$ homologous to the MN-184 isolate used to inoculate the source population. All 6 of the M. hyopneumoniae-positive samples were $99.9 \%$ homologous to $M$. hyopneumoniae 232. These results support the hypothesis that long distance airborne transport of these important swine pathogens can occur.
\end{abstract}

airborne / transport / PRRSV / Mycoplasma

\section{INTRODUCTION}

The ability of livestock pathogens to be transported over long distances via aerosols has been debated for many years [24]. In the literature, there are several reports of long distance airborne spread of a number of bacteria and viruses including foot-and-mouth disease virus (FMDV), Aujezsky's disease virus (ADV), and Mycoplasma hyopneumoniae $[7,15,16]$. Regarding FMDV, using data from

\footnotetext{
* Corresponding author: deexx004@umn.edu
}

actual outbreaks in combination with disease modeling techniques the transport of this virus in aerosol plumes has been predicted to occur up to $60 \mathrm{~km}$ over land and from 100 to $280 \mathrm{~km}$ over the sea $[3,11]$. Similarly, the airborne spread of ADV to 10 farms in the state of Indiana was predicted to occur where the distance between farms ranged from 1.3 to $13.8 \mathrm{~km}$ [17]. Finally, epidemiological studies investigating the spread of $M$. hyopneumoniae between farms indicated that airborne spread was an important risk factor and that the crucial discriminating distance for a farm maintaining

This is an Open Access article distributed under the terms of the Creative Commons Attribution-Noncommercial License (http://creativecommons.org/licenses/by-nc/3.0/), which permits unrestricted use, distribution, and reproduction in any noncommercial medium, provided the original work is properly cited. 
its M. hyopneumoniae-free status was $3.2 \mathrm{~km}$ from other infected farms [16].

Along these lines, it is well documented that specific climatic conditions are important for enhancing the survival of microorganisms in bioaerosols and enhancing long distance airborne spread $[8,10]$. In the case of FMDV, it has been calculated that at a relative humidity of $60 \%$ and a wind velocity of $10 \mathrm{~m} / \mathrm{s}$, the virus could travel over $100 \mathrm{~km}[11,15]$. Other parameters suspected to be risk factors for the airborne spread of this agent include increased cloud cover (70 to $90 \%$ ) resulting in decreased solar UV irradiance [3]. Conditions present during the infection of southern Denmark swine farms with homologous isolates of ADV originating from herds in northern Germany included a marked net airflow (90 to $140 \%$ increase) in directional winds moving from south to north, mean temperatures of 2 to $6{ }^{\circ} \mathrm{C}$ above normal, elevated levels of precipitation and increased cloud cover [7]. Conditions utilized in the modeling of the Indiana outbreak of ADV included directional winds moving in the direction from infected to susceptible farms at speeds of 5 to $6 \mathrm{~m} / \mathrm{s}$, cold temperatures $\left(-11{ }^{\circ} \mathrm{C}\right.$ to $-6{ }^{\circ} \mathrm{C}$ below normal), relative humidity of $85 \%$ with precipitation in the form of fog and rain [17]. Finally, in regards to M. hyopneumoniae, an increased number of suspected cases of airborne spread were reported during the autumn and winter seasons in England during periods of cool, wet weather [16].

Another significant pathogen of swine is porcine reproductive and respiratory syndrome virus (PRRSV) [4]. In an evaluation of risk factors for the spread of PRRSV to sow herds in Denmark, Mortensen suggested that airborne spread was a frequent mode of transmission [22], a hypothesis which was recently validated by Pitkin et al. who demonstrated aerosol transmission of the virus out to $120 \mathrm{~m}$ [25]. However, data regarding long distance airborne transport of PRRSV and the meteorological conditions associated with this event are currently unavailable. Mondaca et al. hypothesized that the presence of prevailing winds may enhance the movement of PRRSV between farms; however, no definitive conclusions could be drawn
[21]. To better understand the role of climate on PRRSV survival in aerosols, Hermann et al. reported half-lives of infectious PRRSV in aerosols ranging from $193 \mathrm{~min}$ at a combined temperature of $5{ }^{\circ} \mathrm{C}$ and a relative humidity of $17 \%$, to $4 \mathrm{~min}$ at $41{ }^{\circ} \mathrm{C}$ and $73 \%$ relative humidity [18]. In addition, using a model of a swine production region, Pitkin et al. reported conditions associated with the presence of PRRSV in air including directional winds of low velocity, low relative humidity and rising barometric pressure [25].

While this information provides preliminary insight into the transport of PRRSV via the aerosol route and its associated meteorological conditions, more data are needed before conclusions can be drawn regarding the pathogen's potential to be transported over long distances via the aerosol route. Furthermore, similar information regarding $M$. hyopneumoniae is needed to support the conclusions drawn from previous studies. Therefore, the purpose of this study is to provide evidence of long distance airborne transport of PRRSV and M. hyopneumoniae and to identify meteorological conditions associated with these events. The study was based on the hypothesis that long distance airborne transport of both agents can occur given the correct conditions.

\section{MATERIALS AND METHODS}

\subsection{Experimental design}

\subsubsection{Description of study site and experimental inoculation}

The study utilized the University of Minnesota Swine Disease Eradication Center (SDEC) research site and $44 \mathrm{~km}^{2}$ of the surrounding landscape located in the west-central region of the state of Minnesota, USA. The topography of the study site was flat with elevations ranging from 304 to $314 \mathrm{~m}$ above sea level. The land consisted primarily of fields used for the raising of corn, soybeans and wheat, pasture for the grazing of cattle and the closest swine farm to the SDEC site was $16 \mathrm{~km}$ to the north, and was known to be free from both PRRSV and M. hyopneumoniae infection. The study was conducted over a 50-day period, beginning on September 30, 2008 
and ending on November 18, 2008. On the SDEC site, a mechanically ventilated grow-finish facility housing a population of 300 grow-finish (25 to $120 \mathrm{~kg}$ ) pigs served as a source of PRRSV and $M$. hyopneumoniae bioaerosols for the surrounding region. Two weeks prior to the onset of the study, 60 out of the 300 pigs were inoculated via the intra-tracheal route with $10 \mathrm{~mL}$ of $M$. hyopneumoniae 232, providing a concentration of $10^{5}$ colorchanging units per $\mathrm{mL}$ per animal [29]. Two weeks later, 100 of the 300 pigs were inoculated via the intra-nasal route with $2 \mathrm{~mL}$ of PRRSV MN-184, providing a total concentration of $2 \times 10^{4} \mathrm{TCID}_{50}$ per animal $[5,6]$. This isolate was selected based on previous studies which demonstrated its ability to be shed at significantly higher frequencies in bioaerosols from experimentally inoculated pigs and a significantly transmission rate to naïve pigs $[5,6]$.

Following inoculation, the experimental PRRSV infection was confirmed by collecting blood samples from 10 of the 100 inoculated animals on day 2 postinoculation and testing sera for the presence of PRRSV RNA by PCR. Similarly, the experimental $M$. hyopneumoniae infection was confirmed by collecting nasal swab samples (BBL CultureSwab, Becton Dickinson, France) from 10 of 60 inoculated animals on day 14 post-inoculation and evaluating them for the presence of $M$. hyopneumoniae DNA, again by PCR. In addition, observation for the presence of clinical signs for PRRSV (weight loss, rectal temperatures of $>40{ }^{\circ} \mathrm{C}$ and elevated mortality) and $M$. hyopneumoniae (coughing) was carried out on a daily basis $[2,14]$. To maintain the circulation of both pathogens within the source population, 3 groups of 20 PRRSV and $M$. hyopneumoniae naïve sentinel animals were introduced to the population every 2 weeks [14]. Ten animals from each of the 20 pig groups were blood tested and nasal swabbed 14 days post-introduction to validate pathogen spread during the study period $[14,25]$. During the entire study, animals were cared for using approved protocols of the University of Minnesota Institutional Animal Care and Use Committee.

\subsubsection{Protocol of air sampling}

To assess the potential for long distance airborne spread of PRRSV and M. hyopneumoniae, a designated sampling area within $44 \mathrm{~km}^{2}$ region around the SDEC site was plotted, consisting of 16 sampling points radiating outward from the source facility in the 4 cardinal directions: north $(\mathrm{N})$, south $(\mathrm{S})$, east (E) and west (W) and the 4 intermediate directions: northwest (NW), northeast (NE), southwest (SW) and southeast (SE). Over the course of the 50-day study period, it was planned to collect air samples at distances of 1.7 and $3.3 \mathrm{~km}$ to the $\mathrm{N}, \mathrm{S}, \mathrm{E}$ and $\mathrm{W}$ of the source population facility, and at distances of 2.6 and $4.7 \mathrm{~km}$ to the NE, NW, SE and SW of the facility (Fig. 1). The sampling points furthest from the source population facility $(3.3 \mathrm{~km}$ and $4.7 \mathrm{~km}$ ) were designated as "A" points, i.e. NW-A, while the points closer to the facility $(1.7 \mathrm{~km}$ and $2.6 \mathrm{~km}$ ) were designated as "B" points, i.e. NW-B. The distance from the source population facility to each sampling point was determined using the odometer of a designated farm vehicle and each point was marked with a fuchsia-colored plastic flag. Daily air samples were collected at a pre-determined direction from the source population facility in accordance with the direction of the predominant wind. This decision was based on the findings of Pitkin et al. who had previously determined that the odds of detecting a PRRSV-positive bioaerosol were 6.4 times higher when the predominant wind was moving from a facility which housed a PRRSV-infected population [25]. Therefore, if the predominant wind direction was from the NW, personnel would collect air samples "downwind" from the source population facility at the SE-A and SE-B sampling points. Wind direction was determined using the wind vane on a HOBO weather station (Onset Computer Corporation, Bourne, MA, USA) which was located on the study site, adjacent to the source population facility.

In regards to the collection of air samples, using sample size tables and an estimated prevalence of $\geq 2 \%$ PRRSV or $M$. hyopneumoniae-positive air samples with a power of 0.8 and alpha of 0.05 , a sample size of 149 samples across the A distances and 149 samples across the B distances was calculated, resulting in a total of 298 long distance air samples. For the collection of air samples, a liquid cyclonic collector capable of capturing $400 \mathrm{~L}$ of air per minute was utilized (Midwest MicroTek, Brookings, South Dakota, USA) [1]. Previous assessment of the instrument's sensitivity for detecting PRRSV in aerosols had been determined it to be $1 \times 10^{1}$ $\mathrm{TCID}_{50} / \mathrm{mL}$ [25]. Throughout the study, the daily collection period was from 5:00 AM CST to 10:00 AM CST with an interval of 30 min per sample [25]. It was planned to collect 3 to 4 samples over the period of 5:00 to 7:00 AM CST at the designated A point and 3 to 4 samples from 7:15 to 9:15 AM CST at the designated B sampling point each day.

To transport the instrument to the designated sampling points, the cyclonic collector was placed in the cab of a farm vehicle (Chevrolet S-10 1987), elevated $25 \mathrm{~cm}$ off the seat by means of a wooden box and 


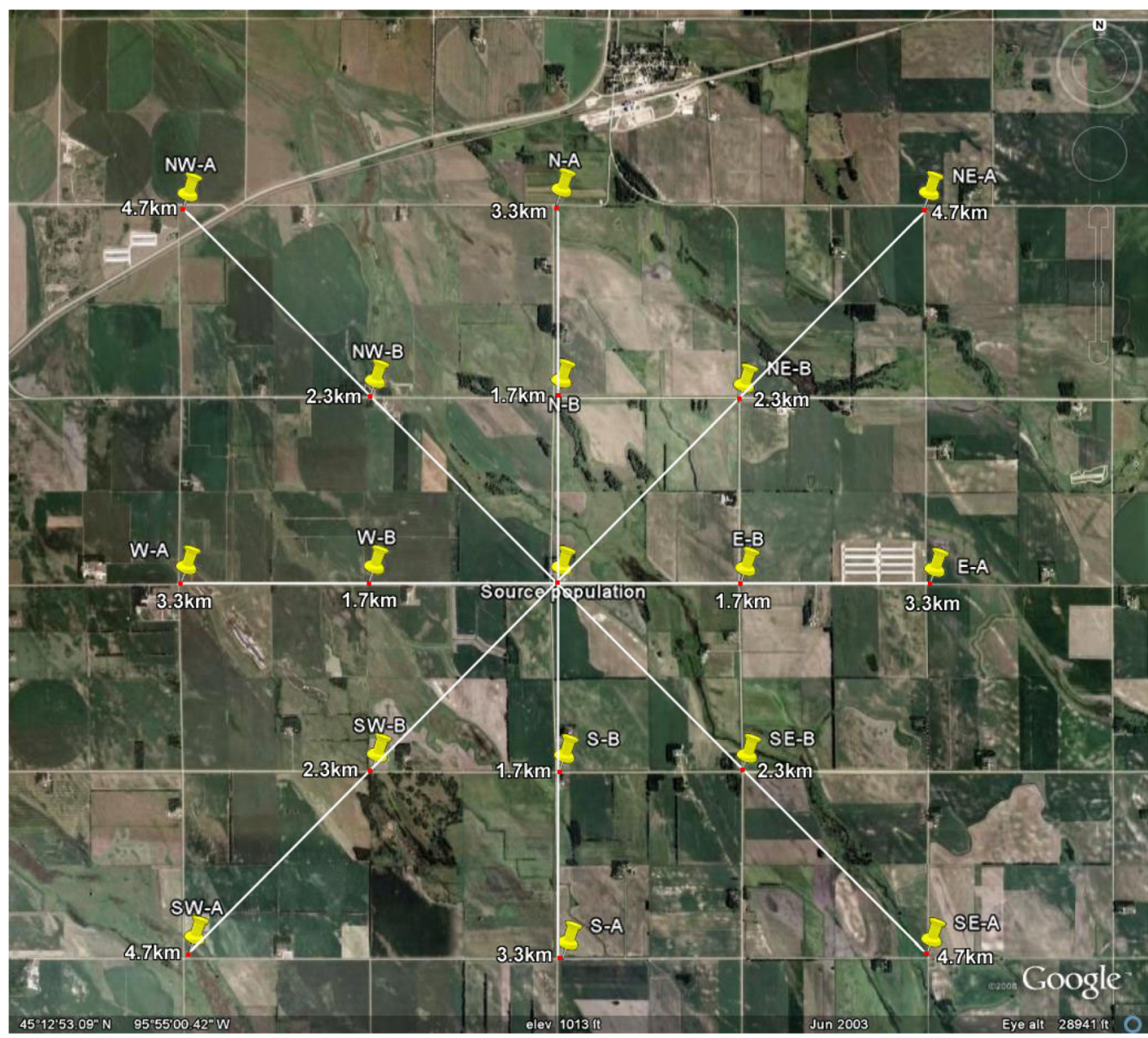

Figure 1. Arial map of sampling area illustrating the points at which air samples were collected in relationship to the source population. Note that the A and B sampling points were located $3.3 \mathrm{~km}$ and $4.7 \mathrm{~km}$ (A points) and 1.7 and $2.3 \mathrm{~km}$ (B points) from the source population, respectively. (A color version of this figure is available at www.vetres.org.)

powered using the vehicle's battery. The dimensions of the vehicle cab were $1.5 \mathrm{~m} \mathrm{H} \times 2 \mathrm{~m} \mathrm{~W} \times 1 \mathrm{~m} \mathrm{~L}$, allowing it to act as a chamber to capture incoming air. Upon arrival to the sampling point, the vehicle was parked with the passenger side of the cab facing directly into the predominant wind. To serve as an air inlet, the passenger window was opened in its entirety while the driver side window was opened approximately $5 \mathrm{~cm}$ to act as an air outlet. During the $30 \mathrm{~min}$ sampling process, airborne particles entering the collection vessel of the cyclonic collector were washed with $10 \mathrm{~mL}$ of minimum essential medium (MEM) supplemented with 3\% fetal calf serum (Difco, Detroit, Michigan, USA). After each
$30 \mathrm{~min}$ sample was collected, a $5 \mathrm{~mL}$ aliquot of MEM was removed and stored on ice until testing was completed each day. To minimize the risk of contamination, study personnel changed gloves and sanitized the collector between air samples [25]. The instrument was sprayed with alkyl dimethly benzyl ammonium chloride (Lysol, Reckitt Benckiser, Wayne, NJ, USA), the collection vessel rinsed with fresh MEM and dried with disposable paper towels and swabbed using sterile Dacron swabs (Fisher Scientific, Hanover Park, IL, USA) [25]. Swabs were stored in sterile plastic tubes (Falcon, Becton Dickinson, Franklin Park, NJ, USA) containing MEM supplemented with $3 \%$ fetal calf serum and stored on ice. 
Upon completion of long distance air sampling, a single $30 \mathrm{~min}$ air sample from the source population was collected from 9:30 to 10:00 AM CST each day. For collection of this sample, the cyclonic collector was placed outside of the source population facility, $1 \mathrm{~m}$ from a designated exhaust fan [25]. All samples were stored at $-20{ }^{\circ} \mathrm{C}$ until tested.

\subsubsection{Controls}

Prior to the initiation of the study, a series of controls were conducted to validate the ability of the collection method to successfully recover aerosolized PRRSV (positive controls) and to demonstrate a lack of mechanical contamination during the sampling process (negative controls). For positive controls, artificial PRRSV aerosols of varying concentrations were developed using a modified live PRRS virus vaccine (Ingel Vac MLV, Boehringer-Ingelheim Vetmedica, St. Joseph, MO, USA) [9]. One hundred $\mathrm{mL}$ aliquots of vaccine virus were diluted 10 -fold in $1 \mathrm{~L}$ aliquots of sterile saline to produce concentrations ranging from $1 \times 10^{1} \mathrm{TCID}_{50} / \mathrm{L}$ to $1 \times 10^{7}$ $\mathrm{TCID}_{50} / \mathrm{L}$. Prior to the initiation of the study, the quantity of virus in each dilution was validated via virus titration [26]. To aerosolize the virus into the vehicle cab, the tank of a cold fog mister (Hurricane ULV/mister, Curtis Dyna-Fog Ltd. Westfield, IN, USA) was filled with $1 \mathrm{~L}$ of each concentration, beginning with $1 \times 10^{1} \mathrm{TCID}_{50}$. The mister was set at a flow rate of $200 \mathrm{~mL} / \mathrm{min}$ and was placed $1 \mathrm{~m}$ off the ground and $1 \mathrm{~m}$ from the vehicle with the nozzle set at a $45^{\circ}$ angle [9]. A 5-min release period was utilized, resulting in the aerosolizing of $1 \mathrm{~L}$ of diluted vaccine [9]. Following release of the aerosolized virus, the cyclonic collector was allowed to run for $30 \mathrm{~min}$ and a $5 \mathrm{~mL}$ aliquot was removed from the collection vessel and stored at $-20{ }^{\circ} \mathrm{C}$. For the purpose of negative controls, the process was repeated 7 times using saline only.

Throughout the study, daily sanitation controls were conducted to validate the absence of residual genetic material in the vehicle and the cyclonic collector. At the conclusion of daily sampling, the entire cab of the vehicle was disinfected with alkyl dimethly benzyl ammonium chloride spray and wiped dry with disposable paper towels. Swabs were then collected from surfaces within the cab including the seat (1 swab), steering wheel (1 swab), accelerator (1 swab), brake (1 swab) and dashboard (1 swab), pooled 5:1 and tested as a single sample [27]. The windows of the cab were closed and the vehicle was stored overnight in the garage on the study site. Then, each day prior to sampling, a $30 \mathrm{~min}$ air sample from the vehicle cab was collected to validate the absence of residual PRRSV or $M$. hyopneumoniae in the cab. During this process, the windows of the cab remained closed and the vehicle remained in the garage. Finally, in between every $30 \mathrm{~min}$ air sample collected during the daily sampling period, the aforementioned cab surfaces and the cyclonic collector were sanitized and swabbed. At the end of each day's sampling period, the vehicle was returned to the garage, disinfected and allowed to sit overnight with its windows closed in preparation for the next day's sampling. The cyclonic collector was then sanitized one final time and stored in the house on the study site overnight. These processes were repeated on a daily basis throughout the 50 day study period and all air samples and swabs were stored at $-20{ }^{\circ} \mathrm{C}$.

\subsection{Diagnostic assays}

\subsubsection{PRRSV and M. hyopneumoniae polymerase chain reaction}

All air and swab samples were tested for the presence of PRRSV RNA by TaqMan qualitative and quantitative polymerase chain reaction (PCR) assays (Applied Biosystems, Foster City, CA, USA) at the Minnesota Veterinary Diagnostic Laboratory using modifications of previously published procedures $[13,19]$. The following primers and probes were used: NA F (ORF 6) forward primer (26 oligomer) $(5$ ' $\rightarrow 3$ ' sequence: GTAGTYGCRCTCCTTTGGGG GGTGTA), NA F2 (ORF 6) forward primer (33 oligomer) (5' $\rightarrow 3$ ': TTCATCACY TCCAGRTGCCGT TTGTGCYTGCTA), NA R (ORF 6) reverse primer (18 oligomer) $\left(5^{\prime} \rightarrow 3\right.$ ' sequence: CGASAAATGCG TGGTTAT). EU (ORF 7) forward primer (19 oligomer) (5' $\rightarrow 3$ ':TGGCCAGCCAGT CAATCAA) EU (ORF7) reverse primer (21 oligomer) ( 5 ' $\rightarrow 3$ ':TGTGG CTTCTCA GGCTTTTTC) PRRS NA/EU FAM labeled ORF6 TAMRA probe (22 oligomer), $\left(5^{\prime} \rightarrow 3^{\prime}\right.$ ': FAM-TACATTCTGGCCCCTGCCCAYC-TAMRA), PRRS EU FAM labeled ORF7 TAMRA probe (25 oligomer $) \quad\left(5^{\prime} \rightarrow 3^{\prime}\right.$ '6FAM-TGCAATGATAAAGTCCC AGCGCCAG-TAMRA). The quantity of infectious PRRSV in PCR-positive air samples was then determined by virus titration [26] using Marc-145 cells and MEM supplemented with $8 \%$ fetal calf serum, antibiotics and antifungal agents. The open reading frame (ORF) 5 region of selected PCR-positive air samples was then nucleic acid sequenced [23]. Sequences were assembled and analyzed using LASERGENE (DNASTAR, Madison, WI, USA). Air and swab samples were also tested for the presence of $M$. hyopneumoniae DNA using a real time PCR at the Minnesota Veterinary 
Diagnostic Laboratory [12]. The following primers and probes were used: forward primer (sequence: 5'TTGACTGCTATCTTTGCACGATAAG-3'), reverse primer (sequence: 5'-ACAATAATTGCTGACCGTG GC-3'), and probe (sequence: FAM-CAAGAAAT CGAATATTTGCAGCAGTGGACA-TAMRA). The DNA from the PCR-positive samples was further characterized via nucleic acid sequencing of the P146 gene [20]. P146 sequences were analyzed using the Bionumerics software v. 5.1 (Applied Math, Austin, TX, USA) analysis and similarities were evaluated done using the Unweighted Pair Group Method with Arithmetic Mean (UPGMA).

\subsubsection{Swine bioassay}

Swine bioassays were conducted to determine whether there was infective PRRSV in PCR-positive air samples [28]. Supernatant $(2 \mathrm{~mL})$ was obtained from individual samples and inoculated via the intra-muscular route into 4 week-old PRRSV-naïve pigs housed individually to prevent direct contact in a high biosecure facility on the SDEC site [25]. This facility utilized an air filtration system having a MERV (minimum efficiency reporting value) rating of 16 (EU 9) known to be capable of preventing the passage of $95 \%$ of particles $\geq 0.3 \mu \mathrm{m}$ in diameter. An additional pig was included as a control and sham inoculated with virus-free MEM. Pigs were blood tested 7 days post-inoculation and serum was stored at $-20{ }^{\circ} \mathrm{C}$ until testing was initiated.

\subsection{Collection of meteorological data}

Meteorological data were collected using an onsite HOBO weather station (Onset Computer Corporation, Bourne, MA, USA). Data were logged at 5 min intervals. The parameters collected included temperature $\left({ }^{\circ} \mathrm{C}\right)$, relative humidity $(\%)$, two measures of sunlight intensity (watts $/ \mathrm{m}^{2}$ ) and photons $\left(\mu \mathrm{mol} / \mathrm{m}^{2} / \mathrm{s}\right)$ within the photosynthetic active radiation spectrum of $400-700 \mathrm{~nm}$, barometric pressure (hectoPascals), precipitation ( $\mathrm{mm}$ of rainfall), wind direction (degrees), wind velocity $(\mathrm{m} / \mathrm{s})$ and wind gusts $(\mathrm{m} / \mathrm{s})$. This latter parameter was defined as the highest 3 -second wind speed recorded during each 5 min logging interval. To provide a numerical value for wind direction, the 4 cardinal and 4 intermediate directions were assigned a range as follows: north (mean $=0^{\circ}$, range $=346^{\circ}$ to $14^{\circ}$ ), northeast $\left(\right.$ mean $=45^{\circ}$, range $=15^{\circ}$ to $\left.75^{\circ}\right)$, east (mean $=90^{\circ}$, range $=76^{\circ}$ to $\left.104^{\circ}\right)$, southeast $($ mean $=1350$, range $=105^{\circ}$ to $\left.165^{\circ}\right)$, south $\left(\right.$ mean $=180^{\circ}$, range $=$ $166^{\circ}$ to $\left.195^{\circ}\right)$, southwest $\left(\right.$ mean $=225^{\circ}$, range $=$ $196^{\circ}$ to $255^{\circ}$ ), west $\left(\right.$ mean $=270^{\circ}$, range $=256^{\circ}$ to $284^{\circ}$ ) and northwest (mean $=315^{\circ}$, range $=285^{\circ}$ to $345^{\circ}$ ).

\subsection{Data analysis}

The days of air sample collection were classified as those days having a positive sample found or as those having a negative sample. The association between PRRSV-positive days and M. hyopneumoniae-positive days at the source population level was tested for significance using a Chi-square test. The association of a pathogen-positive air sample collected at the source population exhaust fan and at long distance sampling points was tested for significance using a Fisher's exact test. Climatic data were averaged over the time of collection on each day and compared with the detection status. Mean wind direction was not analyzed as sampling was based on wind direction. The association between wind direction and PRRSV-positive days and M. hyopneumoniae-positive days was tested using a Chi-square test. Mean values of meteorological variables on PRRSV-positive days or M. hyopneumoniae-positive days were compared to values observed on PRRSVnegative days and $M$. hyopneumoniae-negative days using two sample T-tests (with unequal variances).

\section{RESULTS}

\subsection{Assessment of the source population}

On day 2 post-inoculation, 10/10 blood samples from animals experimentally inoculated with PRRSV MN-184 were found to be PCRpositive. In addition, 7/10 nasal swab samples from animals inoculated with $M$. hyopneumoniae 232 were PCR-positive 14 days post-inoculation. Throughout the study, daily assessment of the source population indicated clinical signs of PRRSV (weight loss, rectal temperatures of $>40{ }^{\circ} \mathrm{C}$, elevated mortality) in approximately $35 \%$ of all pigs present during the study. Clinical signs of $M$. hyopneumoniae (coughing) were observed in approximately $46 \%$ of the animals and a total of $35(12 \%)$ of the animals died during the study period. Circulation of both PRRSV and M. hyopneumoniae was observed in the sentinel animals that entered the source population. This conclusion was based on detection of PRRSV RNA in serum samples 
in $80 \%$ of the pigs in the 3 sentinel groups while $>50 \%$ of sentinels demonstrated evidence of $M$. hyopneumoniae DNA in nasal swabs at 14 days post-placement.

\subsection{Summary of air sampling}

A total of 356 air samples were collected across the 50-day study period, representing approximately $180 \mathrm{~h}$ of sampling time. Fifty of the 356 air samples were collected from the source population exhaust fan and 17 (34\%) were PCR positive for PRRSV RNA while 18 (36\%) were positive for M. hyopneumoniae DNA (Tab. I). Of the 17 samples that contained PRRSV RNA, the mean quantity of infectious virus was $3.9 \times 10^{5}$ TCID $_{50} / \mathrm{mL}$, with a median of $6.0 \times 10^{3} \mathrm{TCID}_{50} / \mathrm{mL}$ and a range of $5.2 \times 10^{1} \mathrm{TCID}_{50} / \mathrm{mL}$ to $2.9 \times 10^{6}$ $\mathrm{TCID}_{50} / \mathrm{mL}$. A total of 306 long distance air samples were collected (153 samples at point $\mathrm{A}$ and $\mathrm{B})$ and $4(1.3 \%)$ were found to be PRRSV PCR-positive. All four samples were obtained on different days: October 5 (6:30 to 7:00 AM), October 6 (6:00 to 6:30 AM), October $22(5: 30$ to 6:00 AM) and November 11 (7:00 to 7:30 AM) and all were detected at the NW collection point at a distance of $4.7 \mathrm{~km}$ from the source population (Fig. 2). All four samples contained infectious PRRSV with the quantity of virus ranging from $3.0 \times 10^{1} \mathrm{TCID}_{50} / \mathrm{mL}, 4.1 \times 10^{1} \mathrm{TCID}_{50} / \mathrm{mL}$, $5.2 \times 10^{2} \mathrm{TCID}_{50} / \mathrm{mL}$ and $7.8 \times 10^{2}$ TCID $_{50} /$ $\mathrm{mL}$, respectively. All four samples contained infectious PRRSV as validated by swine bioassay and no infection was observed in the

Table I. Summary of days when PRRSV and/or M. hyopneumoniae-positive air samples were recovered at specific sampling points.

\begin{tabular}{|c|c|c|c|}
\hline \multirow[t]{2}{*}{ Date } & \multicolumn{3}{|c|}{ Sample } \\
\hline & Source population & $2.3 \mathrm{~km}$ & $4.7 \mathrm{~km}$ \\
\hline $9-30$ & PRRSV/M. hyopneumoniae 5 & neg $^{*}$ & neg \\
\hline $10-2$ & PRRSV & & neg \\
\hline $10-4$ & PRRSV/M. hyopneumoniae & neg & neg \\
\hline $10-5$ & PRRSV/M. hyopneumoniae & M. hyopneumoniae & PRRSV \\
\hline $10-6$ & PRRSV/M. hyopneumoniae & neg & PRRSV \\
\hline $10-7$ & PRRSV/M. hyopneumoniae & neg & neg \\
\hline $10-9$ & PRRSV/M. hyopneumoniae & neg & neg \\
\hline $10-11$ & PRRSV/M. hyopneumoniae & neg & M. hyорпеитопiаe \\
\hline $10-16$ & PRRSV/M. hyopneumoniae & neg & neg \\
\hline $10-17$ & PRRSV/M. hyopneumoniae & neg & neg \\
\hline $10-18$ & PRRSV/M. hyopneumoniae & neg & neg \\
\hline $10-22$ & PRRSV/M. hyopneumoniae & neg & PRRSV/M. hyopneumoniae \\
\hline $10-23$ & neg & neg & M. hyopneumoniae \\
\hline $11-2$ & M. hyopneumoniae & neg & neg \\
\hline $11-3$ & M. hyopneumoniae & M. hyopneumoniae & neg \\
\hline $11-6$ & neg & neg & M. hyopneumoniae \\
\hline $11-10$ & PRRSV & neg & neg \\
\hline $11-11$ & PRRSV/M. hyopneumoniae & neg & PRRSV \\
\hline $11-12$ & PRRSV/M. hyopneumoniae & neg & neg \\
\hline $11-13$ & M. hyopneumoniae & neg & neg \\
\hline $11-15$ & M. hyopneumoniae & neg & neg \\
\hline $11-16$ & PRRSV/M. hyopneumoniae & neg & neg \\
\hline $11-17$ & PRRSV & neg & neg \\
\hline
\end{tabular}

\footnotetext{
* Sample was PRRSV and M. hyopneumoniae negative.
} 


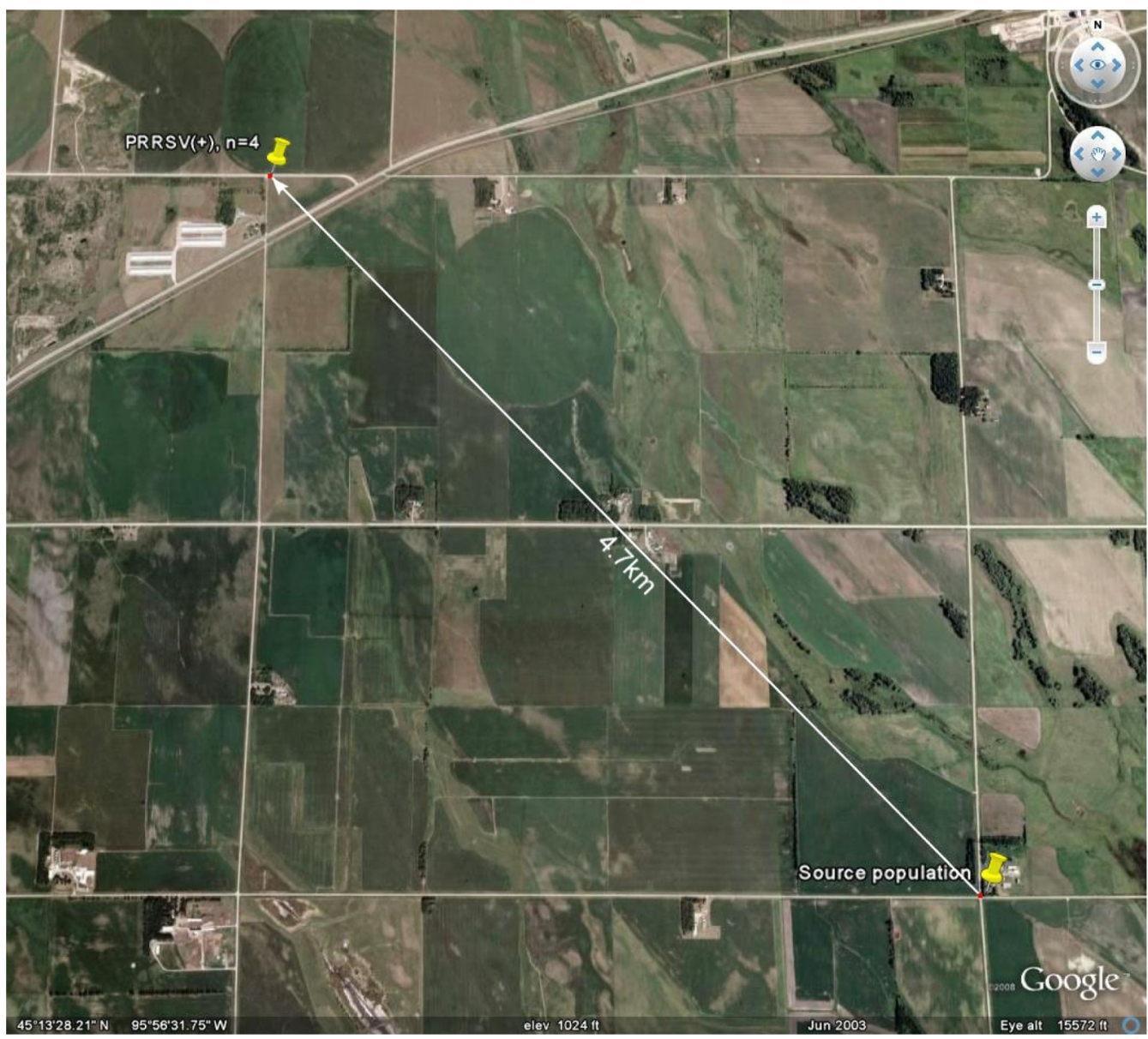

Figure 2. Arial map depicting the location of the sampling point (NW-A) where the 4 PRRSV-positive air samples were recovered in relationship to the source population $4.7 \mathrm{~km}$ away. (A color version of this figure is available at www.vetres.org.)

sham-inoculated control. Phylogenetic analysis of the ORF 5 nucleic acid sequences obtained from a subset of samples including sera from experimentally inoculated pigs, exhausted air from the source population facility and the four samples obtained at the NW collection points were classified as $\mathrm{MN}-184$, based on a high degree of homology $(\geq 98.8 \%)$ with the PRRSV MN-184 isolate that was used to inoculate the animals on day 0 of the study.

Of the 306 long distance air samples collected, $6(1.9 \%)$ were $M$. hyopneumoniae
PCR-positive (Tab. I). All were recovered on different days: October 5 (7:30 to 8:00 AM), October 11 (7:30 to 8:00 AM), October 22 (5:00 to 5:30 AM), October 23 (5:30 to $6: 00$ AM), November 3 (8:00 to 8:30 AM) and November 6 (6:00 to 6:30 AM). Four were obtained at the NW sampling point; with 2 samples collected at the $2.3 \mathrm{~km}$ sampling point and 2 samples at the $4.7 \mathrm{~km}$ sampling point. Of the remaining 2 samples, one sample was obtained at the SE sampling point and the other at the SW sampling point, both points being $4.7 \mathrm{~km}$ 


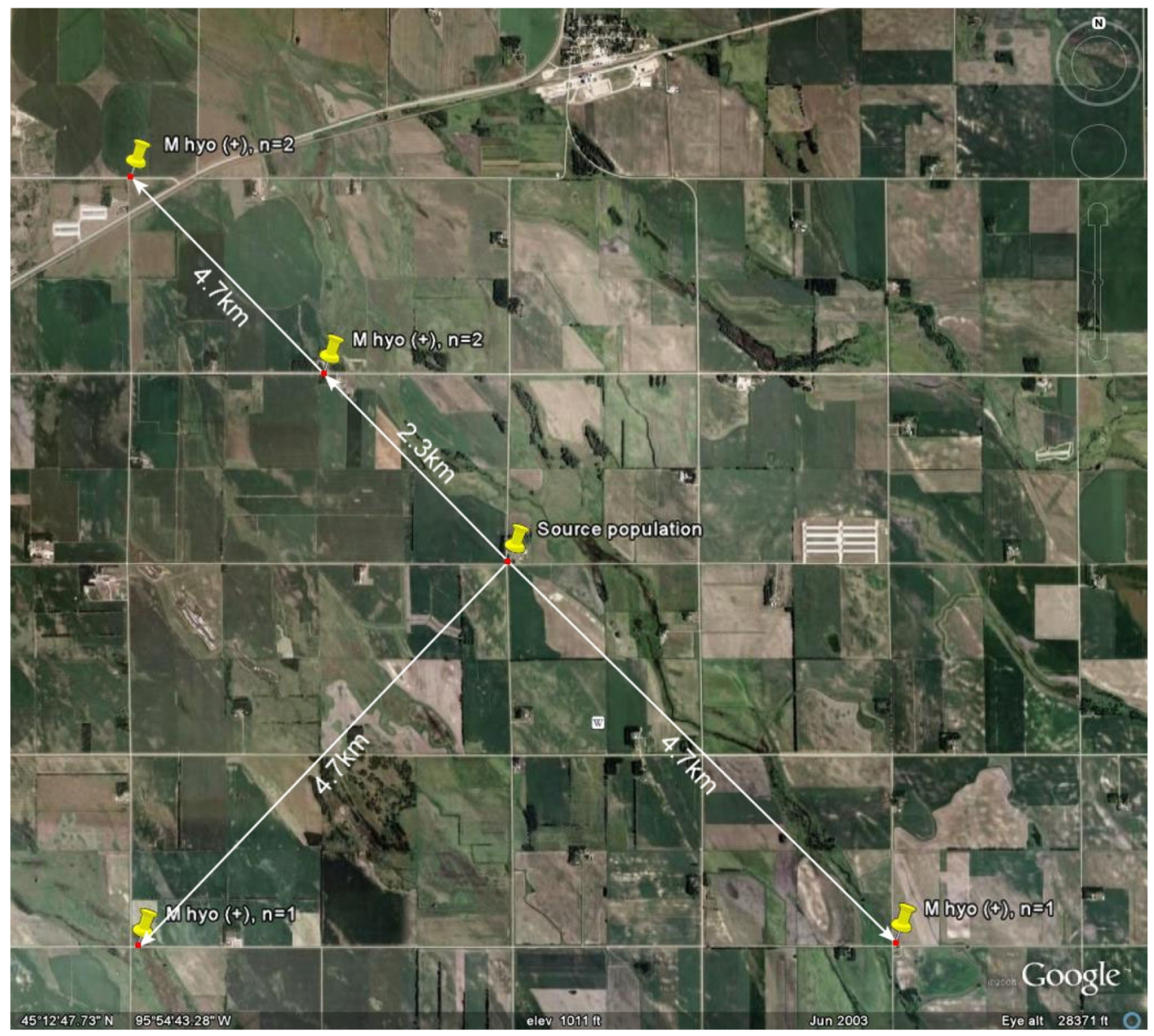

Figure 3. Arial map depicting the location of sampling points where the $6 \mathrm{M}$. hyopneumoniae-positive air samples were recovered in relationship to the source population, 2.3 or $4.7 \mathrm{~km}$ away. (A color version of this figure is available at www.vetres.org.)

from the source (Fig. 3). Phylogenetic analysis of these samples along with positive samples recovered from exhausted air from the source population indicated a high degree $(99.9 \%)$ of homology to the original $M$. hyopneumoniae 232 strain used to inoculate the pigs at the onset of the study.

\subsection{Controls}

The positive control air samples were PCRpositive across all 7 concentrations tested while all 7 negative control air samples (saline only) were PCR-negative. Air samples collected from the enclosed cab of the vehicle prior to daily sampling were PRRSV and $M$. hyopneumoniae PCR-negative ( $n=50$ samples per agent tested) as were all pools of swabs collected from the cab surfaces ( $n=50$ samples per agent tested). In addition, all swabs collected from the cab surfaces between the collection of air samples were PRRSV and M. hyopneumoniae PCRnegative ( $n=306$ samples per agent tested). Finally, all swabs collected from the sanitized 
cyclonic collector between the collection of air samples were PRRSV and M. hyopneumoniae PCR-negative as well $(n=306$ per agent tested).

\subsection{Summary and analysis of meteorological data}

Across the 50-day study period, the origin (directionality) of the winds during the daily sampling periods was as follows: north (2 days, $4 \%$ ), northeast (2 days, 4\%), northwest (21 days, 42\%), southeast (15 days, 30\%), south ( 2 days, $4 \%$ ), southwest (3 days, $6 \%$ ), east (4 days, $8 \%$ ) and west ( 1 day, $2 \%)$. The association between PRRSV-positive days and M. hyopneumoniae-positive days at the level of the source population exhaust fan was significant when tested using a Chi-square test $(p<0.0001)$. The association between the presence of PRRSV in an air sample collected from the exhaust fan and at the $4.7 \mathrm{~km}$ long distance sampling point was significant $(p=0.01)$ using a Fisher's exact test. In contrast, the association between $M$. hyopneumoniae-positive days at the exhaust fan and $M$. hyopneumoniae-positive days at long distance sampling points $(2.3 \mathrm{~km}$ and $4.7 \mathrm{~km}$ combined) was not significant $(p=0.18)$. PRRSV-positive days only occurred when there was a mean NW wind direction $\left( \pm 20^{\circ}\right)$. This association was significant when tested using Chi-square analysis $(p=0.04)$; however, only 4 of the $6 \mathrm{M}$. hyopneumoniae- positive days occurred when the wind direction was NW $(p=0.39)$. Other weather variables were not as strongly associated, but there were associations that need further study. Tables II and III shows the results of two sample $T$-tests (with unequal variances) for these variables.

\section{DISCUSSION}

The objectives of this study were to provide diagnostic evidence of long distance airborne transport of two important pathogens of the porcine respiratory tract and to summarize the meteorological data associated during these events. In regards to the first objective, our data clearly indicate that under the conditions of this study, airborne transport of PRRSV and M. hyopneumoniae occurred out to a distance of $4.7 \mathrm{~km}$, with the results of the controls supporting the fact that the samples contained true positives. Furthermore, the PRRSV RNA and $M$. hyopneumoniae DNA detected in the long distance air samples was highly homologous to that found in samples collected from experimentally inoculated animals and in exhausted air from the facility which housed them, providing a clear indication of the source of the airborne agents. This conclusion is strengthened by data from Table I which indicated a significant association between the presence of both pathogens in air collected from the source population exhaust fan, as well as a significant

Table II. Results of comparisons of mean weather variables between PRRSV-positive and PRRSV-negative days.

\begin{tabular}{lccc}
\hline Variable & \multicolumn{2}{c}{ Air samples } & $p$-Value \\
\cline { 2 - 3 } & PRRSV $(-)$ & PRRSV $(+)$ & \\
\hline Barometric pressure (hectoPascals) & 981 & 982 & 0.83 \\
Temperature $\left({ }^{\circ} \mathrm{C}\right)$ & 3.2 & 7.1 & 0.4 \\
Relative humidity $(\%)$ & 88 & 89 & 0.83 \\
Wind velocity $(\mathrm{m} / \mathrm{s})$ & 1.2 & 2.9 & 0.001 \\
Wind gusts $(\mathrm{m} / \mathrm{s})$ & 2.1 & 4.6 & 0.004 \\
Sunlight intensity (Watts $\left./ \mathrm{m}^{2}\right)$ & 19.0 & 7.2 & 0.06 \\
Sunlight intensity & 51.0 & 21.0 & 0.09 \\
(measure of photons in the visible light & & & \\
spectrum $\left.(400-700 \mathrm{~nm}) \mu \mathrm{mol} / \mathrm{m}^{2} / \mathrm{s}\right)$ & & $7.5 \times 10^{-3}$ & 0.55 \\
Precipitation $(\mathrm{mm})$ & $2.4 \times 10^{-3}$ & & \\
\hline
\end{tabular}


Table III. Results of comparisons of mean weather variables between M. hyopneumoniae-positive and M. hyopneumoniae-negative days.

\begin{tabular}{lccc}
\hline Variable & \multicolumn{2}{c}{ Air samples } & $p$-Value \\
\cline { 2 - 3 } & M. hyopneumoniae $(-)$ & M. hyopneumoniae $(+)$ & \\
\hline Barometric pressure (hectoPascals) & 981 & 978 & 0.45 \\
Temperature $\left({ }^{\circ} \mathrm{C}\right)$ & 3.0 & 7.1 & 0.01 \\
Relative humidity (\%) & 88 & 88 & 0.96 \\
Wind velocity $(\mathrm{m} / \mathrm{s})$ & 1.3 & 3.0 & 0.49 \\
Wind gusts $(\mathrm{m} / \mathrm{s})$ & 2.3 & 4.3 & 0.49 \\
Sunlight intensity (Watts $\left./ \mathrm{m}^{2}\right)$ & 74.3 & 20.1 & 0.0001 \\
Sunlight intensity $\left(\mathrm{measure}^{2}\right.$ of photons & 54.0 & 11.0 & 0.0002 \\
in the visible $\mathrm{light} \mathrm{spectrum}$ & & & \\
$\left.(400-700 \mathrm{~nm}) \mu \mathrm{mol} / \mathrm{m}^{2} / \mathrm{s}\right)$ & & $5.0 \times 10^{-3}$ & 0.66 \\
Precipitation $(\mathrm{mm})$ & $2.5 \times 10^{-3}$ & &
\end{tabular}

association between the detection of a PRRSVpositive air sample at the exhaust fan and at the $4.7 \mathrm{~km}$ sampling point.

It was also interesting to note that all 4 PRRSV samples collected $4.7 \mathrm{~km}$ from the source population facility contained live virus. While we were able to quantify viral load in these samples, we do not known whether they contained sufficient virus to infect animals via the aerosol route due to our inability to house susceptible animals throughout the sampling area and test for evidence of infection. However, if we incorporate meteorological data recorded during the collection of PRRSVpositive aerosols (Tab. II) in conjunction with previously published equations developed to predict the half-life of infectious PRRSV in aerosols [18], at a temperature of $7.1^{\circ} \mathrm{C}$ and relative humidity of $89 \%$ the half-life of infectious PRRSV would be approximately $74 \mathrm{~min}$. Furthermore, at a wind velocity of $3 \mathrm{~m} / \mathrm{s}$, PRRSV could potentially travel the $4.7 \mathrm{~km}$ distance in $26 \mathrm{~min}$, which is well within this estimated $T 1 / 2$ period. It must noted that our sampling region was extremely flat, with virtually no difference in the elevation of the source population site (309 $\mathrm{m}$ above sea level) as compared to the collection points where positive air samples were recovered: NW (310 m), SW (304 m) and SE (308 m). Therefore, similar findings may not have occurred in areas with differing topography, i.e. dense woodlands or elevated terrain.
In regards to the second objective, simple analyses were performed to compare to the weather variables when detection occurred and when it did not. In comparison to our previous report [25], this data set was much more limited by the number of days studied and the number of positive samples, thus limiting the range of analytic methods that could be used and multivariate models were not appropriate in this study. Nonetheless, the strength of association with some variables was surprisingly high. For PRRSV, a higher wind velocity and potentially lower sunlight intensity may have enhanced transport, suggesting that survivability of the PRRSV in aerosols may be limited, and time in the air is a constraint, as is exposure to radiation. Conversely, M. hyopneumoniae appeared to be more strongly associated with low sunlight levels and temperature, with wind speed not being a factor. However, further investigation is needed since numerous other factors which could influence plume dispersal, i.e. shedding patterns of the source population, roughness of the terrain, as well as the stability and the temperature gradient of the lower atmosphere, were not considered in the analysis. Plume dispersal (or lack thereof) may also explain why PRRSV was not detected at the $2.3 \mathrm{~km}$ sampling point which is undoubtedly an artifact of the study.

In conclusion, this is the first report to provide evidence of long distance airborne transport of PRRSV and M. hyopneumoniae. 
This study provides swine veterinarians and producers with proof that long distance airborne transport of economically significant pathogens of swine is possible and identifies meteorological conditions significantly associated with these events. Whether either agent could have been transported beyond the $4.7 \mathrm{~km}$ sampling point cannot be answered at this time; however, future studies involving longer sampling distances and extended sampling periods may help to collect a larger number of samples and answer this question, as well as facilitate a more in-depth analysis of associated meteorological conditions. It is hoped that this information can improve the predictive capability of mathematical models when estimating this risk, with the end result being the delivery of more accurate information to the global swine industry regarding the capability of swine pathogens to be transported over long distances via the airborne route.

Acknowledgements. The authors are grateful to Dr Kurt Rossow and Ms. Carrie Wees of the Minnesota Veterinary Diagnostic Laboratory, Dr Eduardo Fano of PIC Latin America for conducting the experimental inoculation of Mycoplasma hyopneumoniae, as well as Maggie Boerner, Missy Fransen and John Holdvogt for their assistance with the study. Funding was provided by the Boehringer-Ingelheim PRRS Research Initiative and the National Pork Board.

\section{REFERENCES}

[1] Cage B.R., Schreiber K., Barnes C., Portnoy J., Evaluation of four bioaerosol samplers in the outdoor environment, Ann. Allergy Asthma Immunol. (1996) 7:401-406.

[2] Cano J.P., Dee S.A., Murtaugh M.P., Pijoan C., Impact of a modified-live porcine reproductive and respiratory syndrome virus vaccine intervention on a population of pigs infected with a heterologous isolate, Vaccine (2007) 25:4382-4391.

[3] Casal J., Moreso J.M., Planas-Cuchi E., Casal J., Simulated airborne spread of Aujeszky's disease and foot-and-mouth-disease, Vet. Rec. (1997) 140:672676.

[4] Cavanagh D., Nidovirales: a new order comprising Coronaviridae and Arteriviridae, Arch. Virol. (1997) 142:629-633.
[5] Cho J.G., Dee S.A., Deen J., Murtaugh M.P., Joo H.S., An evaluation of isolate pathogenicity on the transmission of porcine reproductive and respiratory syndrome virus by aerosols, Can. J. Vet. Res. (2007) $71: 23-27$

[6] Cho J.G., Dee S.A., Deen J., Trincado C., Fano E., Murtaugh M.P., et al., An evaluation of different variables on the shedding of porcine reproductive and respiratory syndrome virus in aerosols, Can. J. Vet. Res. (2007) 70:297-301.

[7] Christensen L.S., Mousing J., Mortensen S., Soerensen K.J., Strandbygaard S.B., Hemriksen C.A., et al., Evidence of long distance airborne transmission of Aujeszky's disease (pseudorabies) virus, Vet. Rec. (1990) 127:471-474.

[8] Cox C.S., Airborne bacteria and viruses, Sci. Prog. (1989) 73:469-500.

[9] Dee S.A., Deen J., Cano J.P., Batista L., Pijoan C., Further evaluation of alternative air-filtration systems for reducing the transmission of porcine reproductive and respiratory syndrome virus by aerosol, Can. J. Vet. Res. (2006) 70:168-175.

[10] DeJong J.C., Trouwborst T., Winkler K.C., The mechanism of virus decay in aerosols, in: Hers F., Winkler K.C., (Eds.), Airborne transmission and airborne infection, John Wiley and Sons, New York, 1973, pp. 124-130.

[11] Donaldson A.I., Gloster J., Harvey L.D.J., Deans D.H., Use of prediction models to forecast and analyze airborne spread during the foot-and-mouth disease outbreaks in Brittany, Jersey and the Isle of Wight in 1981, Vet. Rec. (1982) 110:53-57.

[12] Dubosson C.R., Conzelmann C., Miserez R., Boerlin P., Frey J., Zimmerman W., et al., Development of two real-time PCR assays for the detection of Mycoplasma hyopneumoniae in clinical samples, Vet. Microbiol. (2004) 19:55-65.

[13] Egli C., Thur B., Liu L., Hoffmann M.A., Quantitative TaqMan RT-PCR for the detection and differentiation of European and North America strains of porcine reproductive and respiratory syndrome virus, J. Virol. Methods (2001) 98:63-75.

[14] Fano E., Pijoan C., Dee S., Infection dynamics of porcine reproductive and respiratory syndrome virus in a continuous-flow population also infected with Mycoplasma hyopneumoniae, Vet. Rec. (2007) 161: 515-520.

[15] Gloster J., Donaldson A.I., Hough M.N., Analysis of a series of outbreaks of Aujeszky's disease in Yorkshire in 1981-1982: the possibility of airborne disease spread, Vet. Rec. (1984) 114:234-239. 
[16] Goodwin R.W.F., Apparent re-infection of enzootic pneumonia-free pig herds: search for possible causes, Vet. Rec. (1985) 116:690-694.

[17] Grant R.H., Scheidt A.B., Rueff L.R., Aerosol transmission of a viable virus affecting swine: explanation of an epizootic of pseudorabies, Int. J. Biometeorol. (1994) 38:33-39.

[18] Hermann J., Hoff S., Munoz-Zanzi C., Yoon K.J., Roof M., Burkhardt A., et al., Effect of temperature and relative humidity on the stability of infectious porcine reproductive and respiratory syndrome virus in aerosols, Vet. Res. (2007) 38:81-93.

[19] Mahlum C.E., Haugerud S., Shivers J.L., Rossow K.D., Goyal S.M., Collins J.E., et al., Detection of bovine viral diarrhea virus by TaqMan reverse transcriptase polymerase chair reaction, J. Vet. Diagn. Invest. (2002) 14:120-125.

[20] Mayor D., Zeeh F., Frey J., Kuhnert P., Diversity of Mycoplasma hyopneumoniae in pig farms revealed by direct molecular typing of clinical material, Vet. Res. (2007) 38:391-398.

[21] Mondaca-Fernandez E., Murtaugh M.P., Morrison R.B., Association between genetic homology of porcine reproductive and respiratory syndrome virus and geographic distance between sites, Can. J. Vet. Res. (2006) 70:237-239.

[22] Mortensen S., Stryhn H., Sorgaard R., Boklund A., Stark K.D., Christensen J., Risk factors for infection of sow herds with porcine reproductive and respiratory syndrome virus (PRRSV), Prev. Vet. Med. (2002) 53:83-101.
[23] Murtaugh M.P., Elam M., Kakach L.T., Comparison of the structural protein coding sequence of the VR-2332 and Lelystad virus strains of the PRRS virus, Arch. Virol. (1995) 140:1451-1460.

[24] Norris K.P., Harper G.J., Windborne dispersal of foot and mouth disease virus, Nature (1970) 225 : 98-99.

[25] Pitkin A.N., Deen J., Dee S.A., Use of a production region model to assess the airborne spread of porcine reproductive and respiratory syndrome virus, Vet. Microbiol. (2009) 136:1-7.

[26] Reed L.J., Muench H., A simple method of estimating fifty percent endpoints, Am. J. Hyg. (1938) 27:493-497.

[27] Rovira A., Clement T., Christopher-Hennings J., Thompson B., Engle M., Reicks D., Munoz-Zanzi C., Evaluation of the sensitivity of a reverse- transcriptase polymerase chain reaction to detect porcine reproductive and respiratory syndrome virus in individual and pooled samples from boars, J. Vet. Diagn. Invest. (2007) 19:502-509.

[28] Swenson S.L., Hill H.T., Zimmerman J.J., Evans L.E., Landgraf J.G., Wills R.W., et al., Excretion of porcine reproductive and respiratory syndrome virus in semen after experimentally induced infection in boars, J. Am. Vet. Med. Assoc. (1994) 15:1943-1948.

[29] Thacker E., Halbur P.G., Ross R.F., Thanawongnuwech R., Thacker B.J., Mycoplasma hyopneumoniae potentiation of porcine reproductive and respiratory syndrome virus-induced pneumonia, J. Clin. Microbiol. (1999) 37:620-627. 